\title{
Medievalista
}

Online

$23 \mid 2018$

Número 23

\section{Lênia Márcia Mongelli, Raúl Cérsar G. Fernandes, Fernando Maués (Eds.), Francisco de Moraes, Palmeirim de Inglaterra}

\section{Geraldo Augusto Fernandes}

\section{(2) OpenEdition \\ Journals \\ Edição electrónica \\ URL: http://journals.openedition.org/medievalista/1678 \\ DOI: 10.4000/medievalista.1678 \\ ISSN: 1646-740X \\ Editora \\ Instituto de Estudos Medievais - FCSH-UNL}

Edição impressa

Data de publição: 1 janeiro 2018

Refêrencia eletrónica

Geraldo Augusto Fernandes, «Lênia Márcia Mongelli, Raúl Cérsar G. Fernandes, Fernando Maués (Eds.), Francisco de Moraes, Palmeirim de Inglaterra », Medievalista [Online], 23 | 2018, posto online no dia 07 maio 2018, consultado o 23 setembro 2020. URL : http://journals.openedition.org/ medievalista/1678; DOI : https://doi.org/10.4000/medievalista.1678

Este documento foi criado de forma automática no dia 23 setembro 2020.

\section{c) (1) 8}

Mediavalista está licenciado com uma Licença Creative Commons - Atribuição-NãoComercial 4.0 Internacional. 


\title{
Lênia Márcia Mongelli, Raúl Cérsar G. Fernandes, Fernando Maués (Eds.), Francisco de Moraes, Palmeirim de Inglaterra
}

\author{
Geraldo Augusto Fernandes
}

\section{REFERÊNCIA}

MONGELLI, Lênia Márcia; FERNANDES, Raúl Cérsar G.; MAUÉS, Fernando (Ed.) Francisco de Moraes, Palmeirim de Inglaterra. São Paulo: Ateliê Editorial / Unicamp, 2016 (744 pp.)

\section{NOTA DO EDITOR}

Data recepção do artigo / Received for publication: 01-04-2017

Fábula bem escrita, ainda que não tenha força de verdade, tem uma ordem de razão. Francisco Rodrigues Lobo ${ }^{1}$

Os editores da obra, inédita no Brasil, Palmeirim de Inglaterra informam que custaramlhes onze anos para a edição definitiva desta novela de cavalaria portuguesa, pertencente ao "ciclo dos Palmeirins" - expressão que designa uma série de novelas que tem origem em Espanha com o primeiro do ciclo, Palmeirín de Oliva, de 1511, provavelmente de Francisco Vásquez, de Salamanca. Deste nasceram outras seis continuações, três delas portuguesas, as outras espanholas. O Palmeirim recentemente editado é da autoria de Francisco de Moraes e aparece pela primeira vez em $1547^{2}$. Diferente das novelas de cavalaria primevas, que tinham uma forte conotação religiosa 
e eram permeadas por ensinamentos cristãos implícitos no enredo das histórias, refletindo o culto à vida espiritual, a busca pela perfeição moral, e a valorização de qualidades morais, as novelas quinhentistas, à parte algumas influências em itens como a honra, bravura, castidade, lealdade, generosidade e justiça, que prevalecem, primam pelo teor profano. Isso, é claro, não impede que os textos sejam permeados por uma certa religiosidade, mas muito mais contida - haja vista essas novelas surgirem na ascensão das ideias renascentistas do século XVI.

O extenso e espesso volume - seu formato é $18 \times 27 \mathrm{~cm}$ - traz em 744 páginas, além do texto narrativo, informações riquíssimas que ajudam o leigo a melhor entender o fenômeno que agradou a um público leitor inumerável, em grande parte constituído por mulheres, na época um "grande consumidor do assunto". O primeiro assunto abordado na introdução intitula-se "O ciclo dos Palmeirins" apresentando toda a historiografia e cronologia dos ciclos arturianos; seguidamente, nas "Informações biográficas", procura-se definir e descrever o autor (cujos dados são ainda nebulosos), profícuo escritor de cartas, diálogos, relações informativas, textos narrativos outros e poesia, além, certo, de narrativas cavaleirescas, cujo Palmeirim é o destaque; segue-se uma extensa e valorosa discussão sobre a questão do fingimento, peculiaridade das novelas de cavalaria - "narração fictícia ou mentirosa, sem garantia histórica, lendária; irrealidade, mentira" (p. 23), como sugere a etimologia de fábula. Além dessa "Introdução", seguem-se explicações sobre a edição atual, bem como a bibliografia selecionada. Antes do texto propriamente dito, esta edição inclui ainda belos fac-símiles das primeiras edições do Palmeirim. Da página 77 à 684, deliciam o leitor as inúmeras narrativas eivadas de aventuras e desaventuras, como não podia deixar de acontecer neste tipo de texto. Compõem ainda o volume um necessário "Glossário" (uma vez que o léxico é ainda quinhentista) com explanações de palavras que hoje não são mais usadas (e.g. trouver em lugar de trazer) e uns "Índices Onomásticos" que explanam as personagens e os topônimos da obra. Entremeiam o texto ilustrações estilizadas de $\operatorname{Audifax}^{3}$ (cuja referência mais precisa se ressente no texto) - diferentemente de se tomarem figuras ou iluminuras próprias da Idade Média, os desenhos modernos, de refinadíssimo bom gosto, trazem um prazer especial à obra.

Em qualquer narrativa cavaleiresca, nenhum herói consegue conquistar sua dama sem antes "provar sua experiência bélica, sua retidão espiritual" (p. 29) - e é esse excesso de aventuras para o feito da conquista que pode afastar o leitor de hoje, uma vez que, por causa do maravilhoso que cerca as novelas, esse mesmo excesso leva a duvidar se a ficção não foi forjada. O extenso enredo do Palmeirim é aparentemente simples: nos primeiros 41 capítulos o autor dá continuidade à história de D. Duardos e de Flérida, pais dos dois heróis gêmeos da novela: Palmeirim e Floriano, raptados por Salvage, e criados por este numa ermida. Os 131 capítulos seguintes entregam-se às aventuras de inumeráveis mini-enredos, que poderiam ser denominados de digressões, que avolumam a obra e, em certa medida, trazem certo cansaço ao leitor desacostumado. Mas o foco da novela é a batalha final entre cristãos e turcos, em que, dos dois lados, computam-se perdas de relevância. Apenas como digressão, e não é exagero, já que se trata de novela cavaleiresca, as batalhas finais nada ficam a dever às batalhas hollywoodianas em que a quantidade de sangue e de mortos excede a racionalidade (o que vai ao encontro da verdade e parte para o essencial do texto cavaleiresco: o fingimento ficcional). 
4 Ao longo das aventuras, o leitor se surpreende pela ekphrasis - os lugares descritos são espaços e geografias bem detalhados, desde florestas que se aproximam do real àquelas encantadas, uma viagem por países que, no modo de relatar, parecem cada um fazer esquina com o outro, castelos ora assombrados ora que beiram a realidade.

Outra questão interessante, e concernente com o estilo de Moraes, é a verborragia para as narrações e descrições. Mario Vargas Llosa, no Prólogo ao Tirant lo Blanc, diz que, além de várias razões de seu deslumbramento pelas novelas de cavalarias, o Tirant em especial, é a descoberta de que as protagonistas da obra são as palavras. É o óbvio em se tratando de literatura. Mas, para o autor peruano, no Tirant, "todos falam até pelos cotovelos, desde o narrador até a última personagem e tudo - as guerras, os desafios, as viagens, as festas, o amor a religião, o prazer, os sofrimentos, é pretexto para intermináveis efusões retóricas" ${ }^{4}$. A isso nada deve o Palmeirim de Inglaterra. Se não pela extensão do texto, também pelo uso esmerado do léxico que Moraes faz. No entanto, há de se considerar alguns pontos quanto a essa verborragia: períodos longuíssimos, inversões e excesso de orações coordenadas dificultam, e muito, a leitura. Além disso, registrem-se os inúmeros flashbacks para, entre as narrativas, encaixar outras narrativas. Se isso agrada (pois o jogo do mise-en-abyme tem por peculiaridade trazer novas expectativas) e provoca alívio no decurso enunciativo, para além de amarrar as pequenas histórias ao assunto central, também resulta em certo tédio na degustação da leitura. A inclusão de novas narrativas vem geralmente explicada pelo narrador por frases como "aqui deixa a história de falar neles e torna aos outros" - o que constitui outro recurso muito usado pelos textos narrativos cavaleirescos.

Voltando a Llosa, o que mais lhe impressionou no Tirant foi a proficuidade de lágrimas e prantos que perpassam por todo o texto. Diz o autor:

"o pranto tem aí ligação exclusivamente com as lágrimas e não com os sentimentos e as emoções, pois estes não existem separados de sua expressão formal, de seu emblema: esses olhos que derramam 'vives llàgremes'. Por isso nesse mundo se chora amiúde socialmente, por razões de cortesia e de mera encenação, como ocorre com o rei Escariano que, ao ver a imperatriz chorando, também se pôs a chorar para fazer-lhe companhia" (p. L).

7 Isso não acontece absolutamente no Palmeirim, apesar das emoções que enlaçam as narrativas; o único momento de pranto em excesso vai ocorrer nos capítulos finais, aquando das duas batalhas entre cristãos e turcos, cujo resultado é um vale de lágrimas escorridas por todos e quaisquer personagens.

8 Ainda quanto ao estilo, Moraes pratica a metalinguagem ao explicar o nome do gêmeo de Palmeirim, Floriano: "Floriano do Deserto, assi pola floresta em que nascera se chamar do Deserto, como por ser em tempo que o campo estava coberto de flores e ele em si tão fermoso, que o nome parecia dino dele e ele do nome" (p. 87). Recurso, claro, mais poético que metalinguístico... Outra recorrência própria dos textos cavaleirescos é a inserção de conselhos, ditos, máximas, ao longo da narrativa (ex: "porque o homem que, vencido de sua vontade, vai contra a virtude, não se deve atrever no merecimento de suas obras" [p. 90]), mas principalmente no final de cada capítulo, como este do Capítulo 45: "que assi são as mudanças desta vida: curar os grandes descontentamentos com descontos de alegrias, e as alegrias torvá-las com descontentamentos; assi que, em suas cousas, pola mor parte sempre pesar vence o prazer" (p. 205). 
Muito chama a atenção nas novelas cavaleirescas a descrição da violência nas batalhas, tanto as coletivas quanto as feitas a pares. Como exemplo, leia-se o enfrentamento de Vernau com o gigante Pândaro, no Capítulo 15:

"Pândaro e ele se andaram ferindo tão bravamente, que Vernau quebrou a espada por o punho nos arcos de ferro na borda do escudo do gigante, de que Pândaro não ficou pouco satisfeito. E deixando cair o seu pelo poder melhor ferir, tomou a maça com ambas as mãos (porque, ainda que Primaleão lhe cortara quatro dedos da mão esquerda na batalha que com ele houve, depois que foi são, a necessidade o ensinou a servir-se dela com engenhos que pera isso buscou); Vernau, que viu sobre si o golpe, juntou-se tanto com ele que lho fez ficar em vão. ${ }^{\text {" }}$

Outro fato a registrar, consiste numa certa comicidade na escolha dos exuberantes nomes das personagens: Avandro, Armião, Drapos, Dramusiando, Frisol, Floramão, Pompides e uma centena de outros, todos exóticos e inverossímeis. Muito interessante, como em qualquer novela de cavalaria, são os motivos (pelo menos uma boa parte deles) dos enfrentamentos: por exemplo, a beleza da mulher servida é tão maior de que qualquer outra, mesmo que todas belas. Esse simplório motivo é o cerne do amor cortesão que perpassa qualquer texto cavaleiresco. Essa questão está ligada ao tema da "contemplação" da amada. Se na poesia trovadoresca a dama era mais imaginada do que real, nas novelas a mesura existe de modo formal, como que um tópico próprio desse tipo de texto. "Nos romances e nas novelas de cavalarias, são conhecidas as "provas" por que têm de passar os cavaleiros enamorados se quiserem receber o galardon de estar com aquela dame sans merci que conheceram não poucas vezes só por "efígie"', conforme escreve Lênia Márcia Mongelli. No Palmeirim essas provas são constantes, mas, ao lutar pelo amor dessa dama servida, o herói não mede esforços para contar como venceu essas provas.

11 Por ser profano, o texto recorre, não com muita intensidade, a situações eróticas, como podemos ver com Floriano do Deserto, num trecho onde é identificado por uma de suas personas, o Salvage, num dos episódios em que salva uma donzela. Ao tirar seu elmo, mostrou-se moço e gentil-homem, o que agradou à moça. Num jogo de olhos e gestos, ora se mostrava ela tímida ora libidinosa. Aparentemente, isso lhe fazia sofrer, mas, como conta o narrador:

"o amor nas mulheres, antes de dar fim ao desejo, não sabe o nome à tristeza; por isso, leda e contente tornava logo a mostrar-se, por não descontentar a ele. Pois como o Cavaleiro do Salvage fosse mestre destes acidentes, com amorosas palavras e afagos necessários a começou tentar, e achando-a mais branda na prática, deu uma pequena de ousadia às mãos, tocando-a nas mangas da roupa e outros lugares onde não parecia desonesto. E sentindo-lhe a vontade entregue, satisfez com seu desejo, de maneira que, quando o escudeiro tornou, era feita dona e bem contente" (p. 393)

Palavras dissimuladas, mas de puro erotismo...

Neste instigante Palmeirim, outras e muitas alusões e reflexões podem ser feitas para se entender ora o que remete ao real ora o que remete ao fingimento ficcional. Entram no conto as posições do senso comum medieval quanto ao papel do velho, como sábio, mas também como instrumento de crítica do autor; não desmerece o fato de o livro, assim como a maioria dos textos medievais, vir eivado de misoginia, apesar de a força da mulher ser evidente por ser o motivo das aventuras e lutas, ela ainda é vista como ser inferior; o preconceito também se revela no texto, principalmente contra a França, caso que aparece em vários capítulos, principalmente naqueles em que se relata a aparição de quatro damas francesas que, belíssimas, levam a lutas pela conquista de seu amor. 
Também interessante é observar certa volubilidade por parte dos heróis que ora lutam pelo amor de uma dama ora por outras, apesar de, no caso dos dois gêmeos principais protagonistas, o seu objetivo era aquelas damas as quais pela primeira vez tocaram-lhes o coração.

O Palmeirim não apenas deve ser lido. Deve ser apreciado e permitir ao leitor de hoje não somente os estudiosos do gênero - conhecer os germes do romance moderno. Apesar de ele ser mais do que isso.

\section{NOTAS}

1. LOBO, Francisco Rodrigues - Corte na aldeia. Lisboa: Verbo, 1972, p. 16.

2. De acordo com os organizadores do volume, "é provável, contudo, que a obra tenha sido impressa pela primeira vez em 1544, edição recentemente descoberta, em português, mas talvez realizada fora de Portugal, em França", p. 12.

3. Trata-se de Audifax Rios (1946-2015), escritor, cordelista e artista plástico cearense, ultimamente cronista do jornal $O$ Povo.

4. Veja-se "Prólogo. TirantloBlanc: as palavras como atos". in MARTORELL, Joanot - Tirant lo Blanc. São Paulo: Ateliê, pp. LI-LII.

5. Observe-se neste trecho a dificuldade que se apresenta ao leitor, um trecho eivado de inversões e de palavras pouco usuais hodiernamente.

6. Veja-se Revista Signum 17 (2016), p. 151 (Resenha).

\section{AUTORES}

\section{GERALDO AUGUSTO FERNANDES}

Universidade Federal do Ceará, Centro de Humanidades / Departamento de Literatura, 60.160-060, Fortaleza, Brasil

geraldoaugust@uol.com.br 